\title{
Successful resection of esophageal carcinosarcoma in presence of right aortic arch: A case report
}

\author{
Zhong-Xi Niu ${ }^{1,2}$, Yao Chen ${ }^{3}$, Jun Peng ${ }^{1}$, Hui Shi ${ }^{1}$, Long-Qi Chen*1 \\ ${ }^{1}$ Department of Thoracic Surgery, West China Hospital, Sichuan University, Chengdu, Sichuan, China \\ ${ }^{2}$ Department of Thoracic Surgery, General Hospital of Chinese Army Police Force, Beijing, China \\ ${ }^{3}$ West China School of Medicine, Sichuna Univeristy, Chengdu, Sichuan, China
}

Received: August 17, 2015

DOI: $10.5430 /$ css.v2n1p52
Accepted: October 30, $2015 \quad$ Online Published: November 9, 2015

URL: http://dx.doi.org/10.5430/css.v2n1p52

\begin{abstract}
We herein report a giant esophageal carcinosarcoma (ECS) occupying the entire intrathoracic esophagus with a coexisting right aortic arch (RAA). The patient was admitted with severe dysphagia and weight loss. Subtotal esophagectomy was performed via left thoraco-cervical approach with cervical esophagogastric anastomosis. The aortopulmonary ligament was ligated and dissected at first for better exposure. Patient recovered uneventfully and there was no evidence of recurrence during the 1 year follow-up period. To our knowledge, this is the first report of such a giant ECS with coexisting RAA. For this kind of patient, a left thoracotomy approach and cervical anastomosis is recommended, and the dissection of aortopulmonary ligament is usually required.
\end{abstract}

Key Words: Esophageal carcinosarcoma, Right aortic arch, Case report

\section{INTRODUCTION}

Esophageal carcinosarcoma (ECS) is a rare esophageal malignant tumor. It comprises approximately $0.36 \%-2.8 \%$ of all esophageal malignancies ${ }^{[1,2]}$ According to a literature search using PubMed, most reported cases were smaller than $17 \mathrm{~cm}$ in length, while a tumor occupying the entire esophagus was quite less frequently seen. ${ }^{[3]}$ Right aortic arch (RAA) is an intrathoracic great vessel anomaly that has been reported to be present in $0.04 \%-0.1 \%$ of autopsy cases. Moreover, the coexistence of ECS with RAA is extremely rare but warrants special awareness during the operation. ${ }^{[4-6]}$ The present case of an ESC occupyping the entire esophagus with coexisting RAA was even more unusual.

\section{CASe Presentation}

A 53-year-old man was admitted to our hospital with complaints of a 20-days history of progressive dysphasia, ac- companied with a weight loss of nearly $10 \mathrm{~kg}$ during the past month. Preoperative TPN was used sometimes in local hospital. Past medical and family history did not include any relevant disease, but was positive for heavy smoking and alcohol consumption. Barium esophagography (see Figure 1A) showed an irregularly-shaped stenosis in the beginning of esophagus. Endoscopy revealed a tumor located at $20 \mathrm{~cm}$ from the incisors, extruding into the esophageal lumen with surface ulceration that prevented passage of the endoscope. The endoscopic biopsy reported a squamous cell carcinoma. The computed tomography (CT) showed a giant intraluminal tumor occupying the full length of intrathoracic esophagus. Furthermore, CT scan demostrated an abnormal intrathoracic great vessel anomaly, the RAA (see Figure 2).

Taking the RAA into consideration, an esophagectomy and lymphadenectomy were performed via left posterolateral

\footnotetext{
${ }^{*}$ Correspondence: Long-Qi Chen; Email: drchenlq@gmail.com; Address: Department of Thoracic Surgery, West China Hospital of Sichuan University, No. 37, Guoxue Alley, Chengdu, Sichuan 610041, China.
} 
thoracotomy through the $5^{\text {th }}$ intercostal space. Firstly, the esophagus was explored and a huge bulk of the tumor was identified with a pedicle originating from the cervical esophagus. The aortopulmonary ligament was dissected before mobilizing the esophagus, in order to obtain satisfactory exposure. The left recurrent laryngeal nerve was not observed around the aortic arch. After mobilization of the esophagus, the left diaphragm was opened and the stomach was mobilized. The gastric tube was formed using a linear stapler along the greater curvature with a diameter of $3 \mathrm{~cm}-4 \mathrm{~cm}$. Through left cervical incision, a hand-sewn esophagogastric anastomosis was performed.

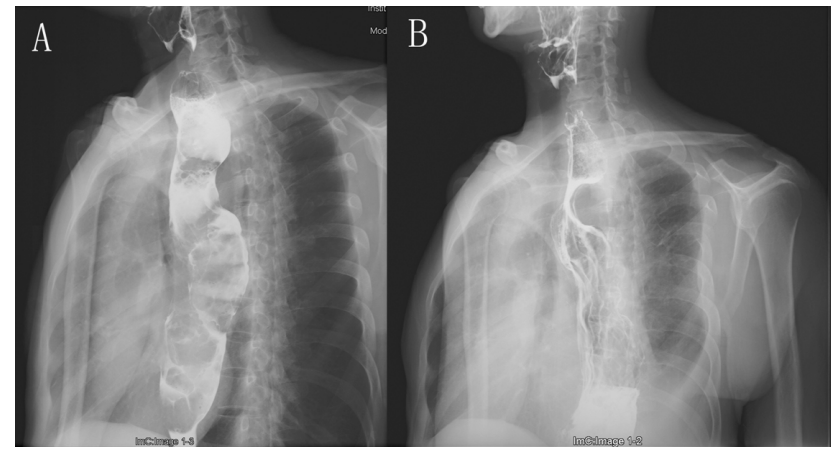

Figure 1. Upper gastrointestinal barium swallow A: the tumor occupies the entire length of the esophagus (preoperative); B: normal anastomosis and intrathoracic mucosa of stomach at two-months follow-up

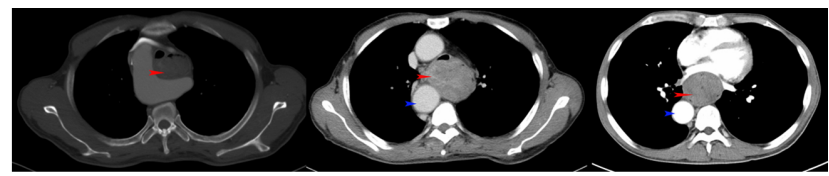

Figure 2. CT scan shows the giant thoracic esophageal tumor with RAA. No enlarged lymph nodes are seen.

Macroscopically, the tumor was $26 \mathrm{~cm} \times 7 \mathrm{~cm} \times 7 \mathrm{~cm}$ in size (see Figure 3). The resected tumor manifested as a lobulated polypoid lesion with a bulk base and submucosal thickening of the esophageal wall. Histologically, the tumor consisted of two components: the squamous cell carcinomatous element and spindle cell sarcomatous element. The tumor infiltrated into muscularis propria and only one of the 23 resected lymph nodes was positive for tumor metastasis. The tumor was then staged as pT2N1M0 (IIB). Immunohistochemistry disclosed that the carcinomatous component was positive for P63, PCK, CK5/6 and the sarcomatous component was positive for SMA. Both components were negative for desmin, S-100, CD117, CD34 and CAM52.

The patient had total parenteral nutritional support for five days and then resumed oral intake. He was discharged un-

Published by Sciedu Press eventfully on the $13^{\text {th }}$ postoperative day. No severe hoarseness was observed. Barium esophagography at 2 months after operation showed a smooth lumen at the anastomosis site without stricture (see Figure 1B). There was no evidence of recurrence at 1 year follow-up.

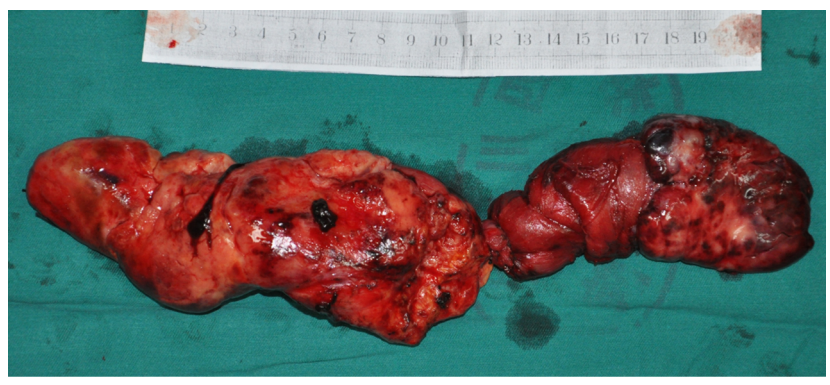

Figure 3. Macroscopic appearance of ECS, measuring $26 \mathrm{~cm} \times 7 \mathrm{~cm} \times 7 \mathrm{~cm}$ in size

\section{Discussion}

ECS is a rare esophageal malignancy, thus there are many aspects that remain unelucidated. Currently, there is no firm conclusion about the histological origin of carcinosarcoma. There are three main hypotheses: collision concept, metaplastic concept and reaction concept, ${ }^{[2]}$ but none of them could clarify all reported cases. In our case, the expression of cytokeratin and SMA were mutually exclusive in the carcinomatous or sarcomatous elements, which may support the collision concept. Immunohistochemistry is the most accurate method for diagnosing carcinosarcoma. ${ }^{[7]}$ The two different components of carcinosarcoma have different specific markers. The cytokeratin and epithelial membrane antigen are the most common markers expressed in the carcinomatous element, while vimentin and SMA are expressed in the sarcomatous element. ${ }^{[8,9]}$ Histological features in the carcinomatous component have variously been described as squamous cell carcinoma or adenocarcinoma. In our case, the carcinomatous component was positive for CK5/6 and the sarcomatous component was positive for SMA, which supported the diagnosis.

In our case, the carcinosarcoma involved the entire thoracic esophagus, thus the patient had severe dysphagia and extreme weakness before surgery. Furthermore, the patient presented with a congenital RAA, thus we chose a left thoracotomy approach and cervical anastomosis for better safey and visibility. To the best of our knowledge, this is the first case in the literature that describes the coexistence of an ECS of this formidable size along with a RAA.

This patient had smoked approximately thirty cigarettes everyday for the past fifteen years. The close link between smoking and esophageal cancers is well-established and doc- 
umented. ${ }^{[10]}$ However, the relationship of smoking and ECS is unclear, although it predominantly affects men. ${ }^{[11]}$

Endoscopic biopsy specimens can be helpful. Sometimes the carcinomatous element may not be obvious, especially in limited biopsies, and the tumor may be mistaken for squamous cancer. On the other hand, the biopsy specimen alone may be mistaken for a pure sarcoma. ${ }^{[12]}$ When sarcomatous components are predominant, the main macroscopic type is polypoid. On the other hand, when carcinomatous components are predominant, the main type is ulcerative. ${ }^{[13]}$ Tumor invasion was limited to the esophageal wall in $80 \%$ of carcinosarcomas and $40.6 \%$ of squamous cell carcinomas. Depth of invasion was limited to the esophageal wall more often in the carcinosarcoma group than in the squamous cell carcinoma group. ${ }^{[14]}$ In our case, although the tumor is so extensive and the patient had severe dysphagia, the tumor was still found to be limited in the deep muscularis propria.

RAA is a rare condition that can be part of a situs inversus syndrome or occurs in isolation. ${ }^{[15]} \mathrm{A}$ few cases of RAA accompanying esophageal cancer have been reported, ${ }^{[4-6]}$ but none of them were ECS. According to the literature, most reported cases of esophageal cancer with coexisting RAA adopted a left thoracotomy approach. ${ }^{[15]}$ In our case, because the entire length of the thoracic esophagus was involved, we adopted a left thoracotomy and left cervical anastomosis. Stomach mobilization was done through the chest instead of abdominal approach according to the custom of Chinese thoracic surgery. Although we didn't identify the left recurrent

\section{REFERENCES}

[1] Kuo CJ, Lin TN, Lin CJ, et al. Clinical manifestation of esophageal carcinosarcoma: a Taiwan experience. Diseases of the Esophagus. 2010; 23: 122-7. PMid: 19473206. http://dx.doi.org/10.11 $11 / j .1442-2050.2009 .00976 . x$

[2] Chandra S, Gorospe EC, Leggett CL, et al. Barrett's Esophagus in 2012: Updates in Pathogenesis, Treatment, and Surveillance. Current gastroenterology reports. 2013; 15: 322. PMid: 23605564. http://dx.doi.org/10.1007/s11894-013-0322-8

[3] Iwaya T, Maesawa C, Uesugi N, et al. True carcinosarcoma of the esophagus. Diseases of the Esophagus. 2006; 19: 48-52. PMid: 16364045. http://dx.doi.org/10.1111/j.1442-2050.2006 $.00538 . \mathrm{x}$

[4] Kanaji S, Nakamura T, Otowa Y, et al. Thoracoscopic esophagectomy in the prone position for esophageal cancer with right aortic arch: case report. Anticancer Research. 2013; 33: 4515-9. PMid: 24123024.

[5] Shimakawa T, Naritaka Y, Wagatuma Y, et al. Esophageal cancer associated with right aortic arch: a case study. Anticancer Research. 2006; 26: 3733-8. PMid: 17094393.

[6] Kubo N, Ohira M, Lee T, et al. Successful resection of esophageal cancer with right aortic arch by video-assisted thoracoscopic surgery: laryngeal nerve, the patient maintained a normal voice after surgery.

ECS has been treated similarly to other esophageal cancers. ${ }^{[16]}$ ECS has a rapid growth, with an average reported doubling time about 2.2 months, ${ }^{[17]}$ which may contribute to its earlier diagnosis compared to other esophageal cancers. Some reports believe ECS has better prognosis owing to its early diagnosis, ${ }^{[2]}$ which may not necessarily be a true association. Lymph node metastasis is a predominant factor in determining the prognosis of esophageal cancer. Sano et al. reported that ECS had a similar lymph node metastasis rate compared with other esophageal cancers, and there was no significant difference between the two in 5-year survival rate. ${ }^{[9]}$ Iyomasa et al. reported similar results. ${ }^{[14]}$ Thus we may take the same therapeutic strategy for the two esophageal cancers. In our case, the patient was found to have metastasis to one lymph node in the fifth group, and we recommended him to receive adjuvant therapy.

In conclusion, this is the first case report of an ECS occupying the entire intrathoracic esophagus with a co-existed RAA. The choice of surgical approach should take into consideration the abnormal great vessel, and therefore a left thoracotomy and cervical anastomosis might be optimal. However, further investigations are warranted to better characterize ECS to guide clinical practice, especially concerning adequate postoperative adjuvant therapy.

\section{CONFlicts of InTEREST Disclosure}

The authors declare no conflicts of interest. a case report. Anticancer Research. 2013; 33: 1635-40. PMid: 23564808 .

[7] Xu F, Zou WB, Li XP, et al. Multiple carcinosarcomas of the esophagus and stomach. Oncology Letters. 2013; 5: 1017-21. PMid: 23426899.

[8] Handra-Luca A, Terris B, Couvelard A, et al. Spindle cell squamous carcinoma of the oesophagus: an analysis of 17 cases, with new immunohistochemical evidence for a clonal origin. Histopathology. 2001; 39: 125-32. PMid: 11493328. http://dx.doi.org/10.10 $46 / j .1365-2559.2001 .01174 . x$

[9] Sano A, Sakurai S, Kato H, et al. Clinicopathological and immunohistochemical characteristics of esophageal carcinosarcoma. Anticancer Research. 2009; 29: 3375-80. PMid: 19661359.

[10] Tramacere I, La Vecchia C, Negri E. Tobacco smoking and esophageal and gastric cardia adenocarcinoma: a meta-analysis. Epidemiology (Cambridge, Mass). 2011; 22: 344-9. PMid: 21330928. http://dx.doi.org/10.1097/EDE.0b013e31821092cd

[11] Madan AK, Long AE, Weldon CB, et al. Esophageal carcinosarcoma. Journal of Gastrointestinal Surgery. 2001; 5: 414-7. http: //dx.doi.org/10.1016/S1091-255X(01)80071-8 
[12] Raza MA, Mazzara PF. Sarcomatoid carcinoma of esophagus. Archives of Pathology \& Laboratory Medicine. 2011; 135: 945-8. PMid: 21732788.

[13] Yamamoto Y, Watanabe Y, Horiuchi A, et al. True carcinosarcoma of the esophagus: report of a case. Case Reports in Gastroenterology. 2008; 2: 330-7. PMid: 21490865. http://dx.doi.org/10.1159 1000151584

[14] Iyomasa S, Kato H, Tachimori Y, et al. Carcinosarcoma of the esophagus: a twenty-case study. Japanese Journal of Clinical Oncology. 1990; 20: 99-106. PMid: 2319703.

[15] Zhong-Xi N, Qiang G, Jun P, et al. Diagnosis and surgical treat- ment of esophageal carcinoma with coexistent intrathoracic vascular malformations. Thoracic Cancer. 2014; 5: 377-82. http: //dx.doi.org/10.1111/1759-7714.12103

[16] Akagi I, Miyashita M, Makino H, et al. So-called carcinosarcoma of the esophagus: report of a case. Journal of Nippon Medical School. 2008; 75: 171-4. PMid: 18648176. http://dx.doi.org/10.12 $72 /$ jnms. 75.171

[17] Sasajima K, Taniguchi Y, Morino K, et al. Rapid growth of a pseudosarcoma of the esophagus. Journal of Clinical Gastroenterology. 1988; 10: 533-6. PMid: 3183327. http://dx.doi.org/10.1097 /00004836-198810000-00011 